\title{
Analysis of the efficiency of a hybrid foil tunnel heating system
}

\author{
Stawomir Kurpaska ${ }^{1, *}$, and Norbert Pedryc ${ }^{2}$ \\ ${ }^{1}$ University of Agriculture in Krakow, Faculty of Production Engineering and Energetics, Institute of Agricultural Engineering and \\ Informatics, Balicka st. 116B, Cracow, Poland \\ ${ }^{2}$ University of Agriculture in Krakow, Faculty of Production Engineering and Energetics, Departament of Mechanical Engineering \\ and Agrophysics, Balicka st. 120, Cracow, Poland
}

\begin{abstract}
The paper analyzes the efficiency of the hybrid system used to heat the foil tunnel. The tested system was built on the basis of heat gain in a cascade manner. The first step is to heat the water in the storage tank using the solar collectors. The second stage is the use of a heat pump (HP) in order to heat the diaphragm exchangers. The lower HP heat source is a cascade first stage buffer. In the storage tank, diaphragm exchangers used for solar collectors and heat pumps are installed. The research was carried out at a research station located in the University of Agriculture in Cracow. The aim was to perform an analysis of the efficiency of a hybrid system for the heating of a foil tunnel in the months from May to September. The efficiency of the entire hybrid system was calculated as the relation of the effect obtained in reference to the electrical power used to drive the heat pump components (compressor drive, circulation pump), circulation pumps and fans installed in the diaphragm heaters. The resulting effect was the amount of heat supplied to the interior of the object as a result of the internal air being forced through the diaphragm exchangers.
\end{abstract}

\section{Introduction}

The dynamic economic development of the country has caused a significant increase in energy demand. Energy demand should be understood as energy in the basic forms - thermal energy and electricity. In order to neutralize and reduce the amount of waste and sewage, energy expenditure is required to generate higher fuel demands. The economy of our country is mainly based on the conventional fuels such as liquid fuels, gaseous fuels and in the greatest part solid fuels in the form of hard coal. In recent years, there has been considerable interest in renewable energy sources (RES), including for the heating of gardening facilities. These studies were conducted in numerous scientific center. And so, Garcia et al. [1] analyzed the possibility of using different heat sources (traditional and renewable) for heating greenhouses located in different climatic conditions. They noted that under the European climate conditions in the Mediterranean countries the best use would be the use of solar collectors, while for countries located in the northern regions it is best to support heating by means of a heat pump. They have identified the need to store excess of energy generated by the passive heating of greenhouse interiors in energy accumulators. Rousse et al. [2] presented the results of long-term research on heat recovery through greenhouse ventilation. The bed was installed in the exchanger that condensed the vapor contained in the moist air. Dried air was injected into the object. Ossebaard et al. [3] presented an analysis of the use of particular energy sources for heating (both renewable and traditional) with regard to economic and ecological effects. Hamdan et al. [4] analyzed the use of renewable energy sources for heating greenhouses. The performance of independent sources (heat pump, solar collectors) and bivalent hybrid systems were analyzed as a combination of a pump with solar collectors. Gustavsson et al. [5] have shown the benefits of substituting traditional heat carriers for the conversion of biomass to both heating and fuel transport. The authors have shown that the need for renewable sources of energy, and the resulting benefits have counted into the reduction of harmful substances emitted into the atmosphere. Groscurth et al. [6] presented problems with the use of renewable energies for heating purposes, paying attention to the rational separation of existing renewable energy sources in order to minimize the emission of harmful substances generated during the combustion of conventional heat carriers. The financial implications of the reduction of environmental pollution have also been taken into consideration. Huang and Lee [7], based on long-term studies, have determined the consumption of electricity used to drive the heat pump. The calculations were conducted with respect to the unit increment of the temperature of the liquid stored in the buffer tank of the heat pump. Kaygusuz and Ayhan [8] described and analyzed the heat pump co-operation system in which as the bottom source was used atmospheric air, with the upper one, where energy was stored in a battery filled with a phase-changeable state.

\footnotetext{
Corresponding author: rtkurpas@cyf-kr.edu.pl
} 
Nagano et al. [9] have developed an innovative system for visualizing and analyzing the efficiency of the heat pump operation, using a ground exchanger as the bottom source. The heat pump was used for heating purposes of the prototype greenhouse. Hawlader et al. [10] studied the energy effects of a system in which a heat pump cooperated with a solar collector. Fuller [11] analyzed theoretically and performed an experimental verification of the system using heated water in solar collectors for heating the foil tunnel. The water was collected in an accumulation tank and hence was directed (in a closed system) for washing out the surface covering the object.

The energy efficiency of the system has been determined, indicating its usefulness in high radiation areas. Kurpaska [12] presented an economic and ecological analysis of the heat pump (co-operating with the ground exchanger) for heating the foil tunnel. In summary, the problem of the use of heat pumps is a current issue in various scientific institutions. Analyzing this issue will be the main aim of presented work.

\section{Purpose and scope of work}

The purpose of the study was to analyze the efficiency of the hybrid system for the heating of the foil tunnel in selected months. As input variables for the analyzed system were separated:

- The energy of solar radiation,

- The energy generated from solar collectors,

- The energy absorbed by the heat pump from the lower heat source,

- The energy supplied to the facility through heat exchangers.

\section{Methodology of research}

The research was carried out at the research station owned by the Faculty of Production Engineering and Energetics of the University of Agriculture in Cracow. Fig. 1 shows a diagram of the analyzed hybrid system.

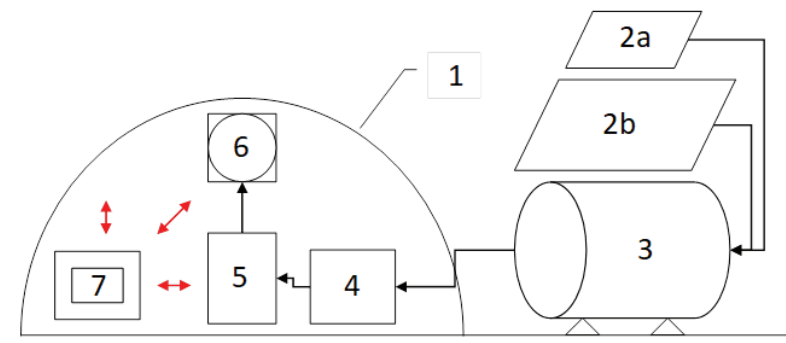

Fig. 1. Diagram of the measurement station: 1 - foil tunnel; 2a, $2 \mathrm{~b}$ - solar collectors; 3 - accumulation tank; 4 - heat pump; 5 buffer tank; 6 - heat source exchangers with fan; 7 - measuring and control equipment.

Heat from the compressor heat pump (type Vatra 10B1), through two diaphragm exchangers (6), was delivered to the interior of the foil tunnel (tunnel measuring $9 \times 6 \mathrm{~m}$ and $2.5 \mathrm{~m}$ high, covered with 0.18 $\mathrm{mm}$ PE foil). Water in the accumulation tank (3) was the lower heat source of the compressor pump (4) which cooperated with the buffer tank (5). Water heating in the receiver (3) took place using solar collectors (vacuum and flat collectors). Flat collector area was $7.8 \mathrm{~m}^{2}$, and vacuum collectors $4.3 \mathrm{~m}^{2}$.

The system was supplemented by a control and measuring system, which monitored the necessary parameters at a present frequency and controlled the operation of the heat pump components. The study was conducted for the period from April to September, and for further analysis were selected days differing in the parameters of the surrounding climate.

Calculations of significant values characteristic for the efficiency of the bivalent system in differential time $d \tau$ were made on the basis of the following equations:

- Solar radiation energy Es:

$E_{s}=\sum_{i=1}^{n} R_{z} \cdot F_{k} \cdot d \tau[\mathrm{J}]$

- Energy gained from solar collectors Qk:

$Q_{k}=\sum_{i=1}^{n} m_{c z} \cdot c_{c z} \cdot\left(T_{p}-T_{z}\right) d \tau[\mathrm{kWh}]$

- $\quad$ Efficiency of solar collectors $\eta \mathrm{k}$ :

$\eta_{k}=\frac{Q_{k}}{E_{s}} \cdot 100 \%$

- The energy supplied to the $Q z b d$ accumulation tank:

$$
Q_{z b d}=m_{w o d} \cdot c_{w o d} \cdot\left(T_{z b \max }-T_{p o c z}\right) d \tau \quad[\mathrm{kWh}]
$$

- $\quad$ The energy collected by the heat pump from the heat source Qdź:

$$
Q_{d z}=\sum_{i=1}^{n} m_{c z} \cdot c_{c z} \cdot\left(T_{z}-T_{p}\right) d \tau \quad[\mathrm{kWh}]
$$

- $\quad$ The energy supplied to the object through $Q g z \dot{z}$ heat exchangers:

$$
Q_{g z}=\sum_{i=1}^{2}\left(\sum_{i=1}^{n} m_{c z} \cdot c_{c z} \cdot\left(T_{z}-T_{p}\right)\right) d \tau[\mathrm{kWh}]
$$

- $\quad$ The demand for heat $Q_{o b}$ :

$Q_{o b}=\sum_{i=1}^{n} k_{o s t} \cdot F_{o s t} \cdot\left(T_{o b}-T_{o t}\right) d \tau[\mathrm{kWh}]$

- $\quad$ Heat pump efficiency coefficient COP:

$$
C O P=\frac{Q_{g \dot{z}}}{P_{p c} \cdot \tau_{p c}}
$$

where:

$R_{z}$ - intensity of solar radiation, $\left[\mathrm{W} \cdot \mathrm{m}^{-2}\right] ; F_{k}$ - surface $\left[\mathrm{m}^{2}\right], \tau$ working time $[\mathrm{h}], \mathrm{m}_{\mathrm{cz}}-$ stream of medium $\left[\mathrm{kg} \cdot \mathrm{s}^{-1}\right], \mathrm{c}_{\mathrm{cz}}-$ the 
specific heat of the liquid $\left[\mathrm{J} \cdot \mathrm{kg}^{-1} \cdot \mathrm{K}^{-1}\right]$, T- temperature, where; subscript: $z, p$ supply and return circulating medium, $o b$ - inside the tunel, ot- ambient $\left[{ }^{\circ} \mathrm{C}\right], k_{o s t}$ heat transfer coefficient $\left[\mathrm{W} \cdot \mathrm{m}^{-2} \cdot \mathrm{K}^{-1}\right], \tau_{P C^{-}}$heat pump working time $[\mathrm{h}]$, $P_{p c}$ - heat pump power $[\mathrm{kW}]$.

\section{Research results}

Fig. 2 shows the calculated efficiency of solar collectors.

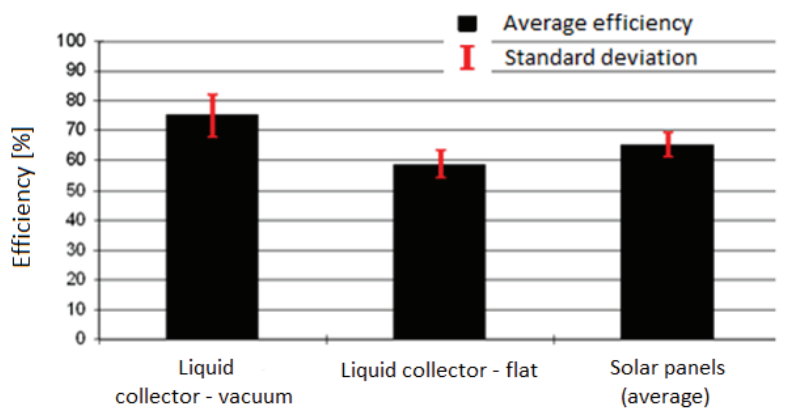

Fig. 2. Efficiency of the analyzed solar collectors.

The highest efficiency have shown vacuum collectors with an average level of about $75 \%$, while the average performance of flat collectors was in the analyzed period, with efficiency close to $60 \%$. The average difference between the efficiency of the collectors was $15 \%$ (standard deviation $11.67 \%$ ). The calculated overall average efficiency of the solar conversion system, calculated as the arithmetic mean of the efficiency of both types of solar collectors, was approximately $65 \%$ from each of the system cycles studied.

Fig. 3 shows the effect of the sum of solar radiation on the amount of energy supplied to the storage tank during the surveyed cycles (the sum of solar radiation and energy were calculated for the period of system operation). The amount of this energy was strictly dependent on the work of the solar collectors. The energy losses that occurred when the tank was loaded were at an average level of $6.37 \mathrm{kWh}$ (standard deviation of $3.09 \mathrm{kWh}$.) With the increase in solar radiation, the value of these losses increased.

Fig. 4 shows the correlation between the sum of solar radiation and the energy supplied to the accumulation tank by the solar collectors and the energy received by the heat pump from it during the tested measurement cycles (the sum of solar radiation and energy was calculated for the period of system operation cycle). It can be noticed that the amount of energy consumed from the lower heat source by the heat pump is approximately constant throughout the range (on average $31.45 \mathrm{kWh}$ at standard deviation of 3.84).

Fig. 5 illustrates the effect of the heat pump operating time on the amount of energy it consumes from the accumulation tank during the measured cycle tests (working time and energy were calculated for the system cycle period).

During the longer operation of the heat pump, more energy was drawn from the bottom of the heat pump. The calculations showed that the average energy consumption from the accumulation tank, per hour of operation, was about $2.5 \mathrm{kWh}$ of heat.

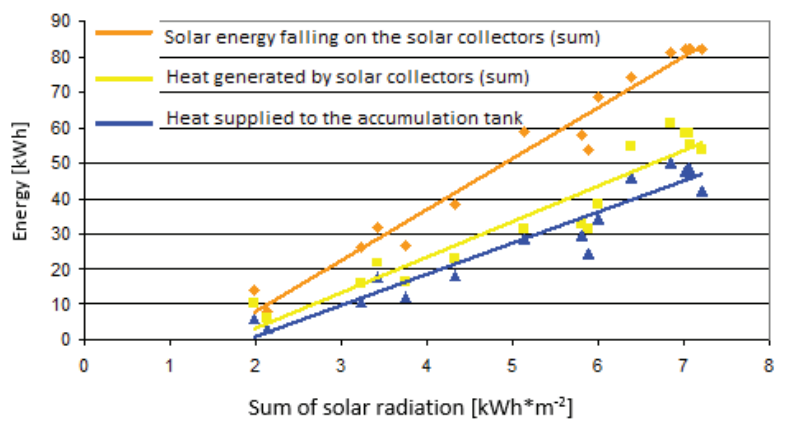

Fig. 3. The effect of total solar radiation on changes in energy components in the system.

In a given system configuration, the amount of heat supplied by the solar collectors to the storage tank, which would balance the energy taken from it by the heat pump, was only reached at a total solar radiation of approximately $5.5 \mathrm{kWh}$.

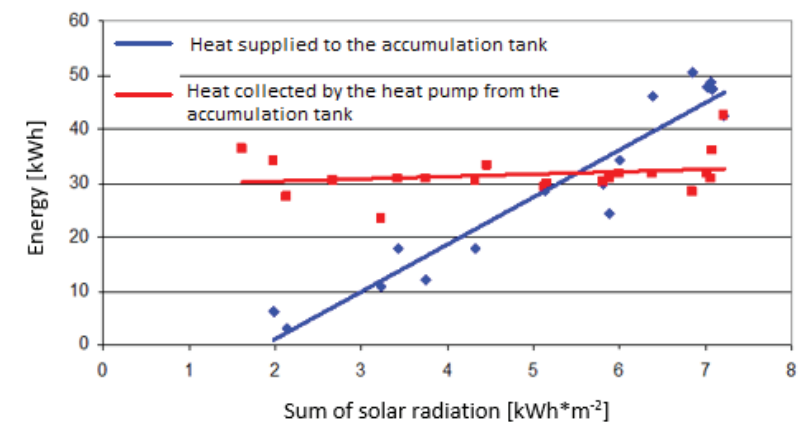

Fig. 4. The dependence of the energy supplied to the accumulation tank and the energy received from it by the heat pump as a function of the sum of solar radiation.

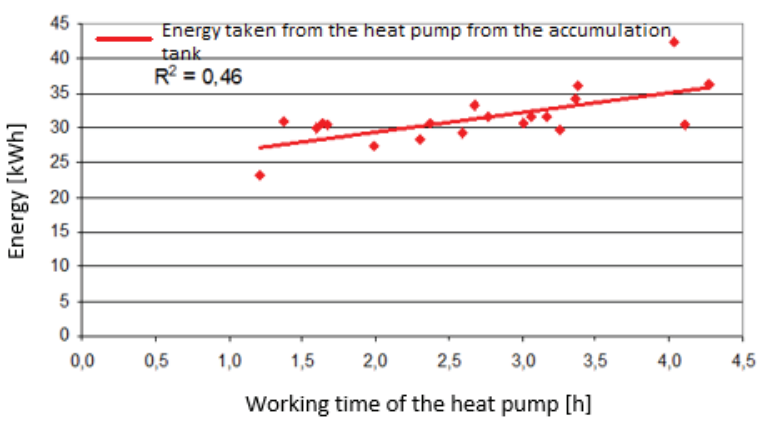

Fig. 5. Energy collected from the accumulation tank by the heat pump as a function of the system operating time.

Fig. 6 illustrates the amount of energy in the lower and upper heat sources of the heat pump with respect to the heat demand of the object (the heat demand was calculated during the operation of the liquid-air heat exchangers for the assumed temperature of $15^{\circ} \mathrm{C}$, while the energy was calculated for the period of system operation). The heat that was collected by the heat pump 
from the accumulation tank could theoretically be sufficient to meet the heat demand of the object at the level of up to $0.5 \mathrm{kWh} \cdot \mathrm{m}^{-2}$. In calculations, the heat transfer coefficient of the object was $7\left[\mathrm{~W} \cdot \mathrm{m}^{-2} \cdot \mathrm{K}^{-1}\right]$. It should also be noted that the difference between the heat values collected by the heat pump and the heat supplied to the object was the smaller the higher the heat demand (lower outdoor temperature).

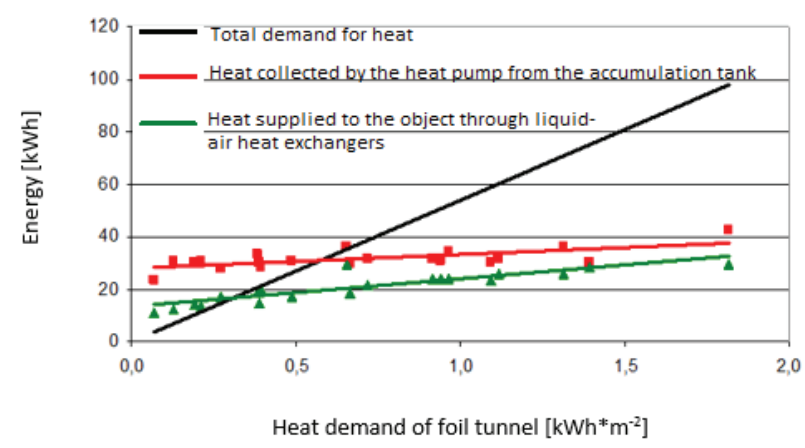

Fig. 6. Energy taken from the lower heat source by the heat pump and the energy supplied to the interior of the object by liquid-air heat exchangers as a function of the heat demand of the object.

Fig. 7 depicts the influence of the average temperature of the lower heat source on the efficiency of the hybrid system and the heat pump during the test cycles (temperature and efficiency were calculated for the system cycle period).

The temperature of the water stored in the accumulation tank had a significant effect on the heat pump's operation. Higher water temperatures increased the efficiency of the heat pump by improved heat exchange and associated with this shorter operating time (heat pumps).

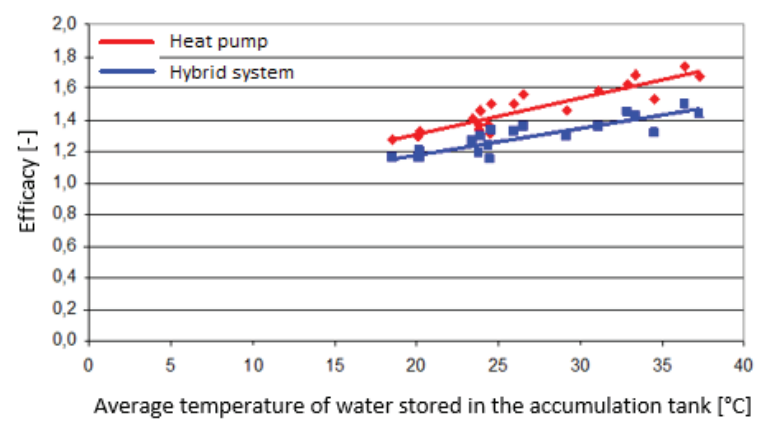

Fig. 7. Efficiency of the hybrid system and the heat pump as a function of the average temperature of water stored in the accumulation tank

Therefore the value of this coefficient affected significantly not only the efficiency of the heat pump but, also the entire hybrid system since two are highly correlated with each other. Increasing the water temperature inside the accumulation tank by $5{ }^{\circ} \mathrm{C}$ resulted in an average increase in efficiency of the entire system by 0.1 . Under the tested conditions, the average efficiency of the heat pump was 1.51, while the overall system (including the power consumed by circulation pumps of diaphragm exchangers) was about 1.48.

\section{Conclusions}

1. The efficiency of the solar conversion system for the period under review was about $65 \%$ on average (average solar collector efficiency was $75 \%$ for vacuum collector and $60 \%$ for flat collector respectively).

2. The average value of energy losses when charging the accumulation tank was about $6.37 \mathrm{kWh}$. With the increase in the sum of solar radiation, the value of these losses increased.

3. The amount of energy consumed from the lower heat source by the heat pump is approximately constant throughout the range (average $31.45 \mathrm{kWh}$ at standard deviation of 3.84). With the analyzed configuration of the system, the amount of heat supplied by the solar collectors to the accumulation tank, which would balance the energy taken from it by the heat pump, was only achieved at a total solar radiation of about $5.5 \mathrm{kWh}$.

4. Under the test conditions, the average efficiency of the heat pump was 1.51 , while the overall system (including the power taken from the circulation pumps of the diaphragm exchangers) was about 1.48.

The Research was financed by the Ministry of Science and Higher Education of the Republic of Poland.

\section{References}

1. J.L. Garcia, S. De la Plaza, L.M. Navas, R.M. Benavente, L. Luna, J. Agric. Eng. Res. 69, pp. 107114, (1998)

2. D.R. Rousse, D.Y. Martin, R. Theriault, F. Leveillee, R. Boily, App. Therm. Eng 20, pp. $687-$ 706, (2000)

3. M.E. Ossebaard, A.J.M. Van Wijk, M.T. Van Wees, Energy 22, pp. 1087- 1098, (1997)

4. M.A. Hamdan, A.I. Al-Sayeh, B.A. Jubran, App. Energy 41, pp. 251- 264, (1992)

5. L. Gustavsson, P. Svenningsson, Energy Conv. Man. 37, pp. 1211-1216, (1996)

6. H.M. Groscurth, T. Bruckner, R. Kummel, Energy 18, pp. 1187- 1205, (1993)

7. B.J. Huang, C.P. Lee, Ren. Energy 29, pp. 633- 639, (2004)

8. K. Kaygusuz, T. Ayhan, Energy Conv. Man. 40, pp. 1377-1396, (1999)

9. K. Nagano, T. Katsura, S. Takeda, App. Therm. Eng. 26, pp. 1578-1592, (2006)

10. M.N.A Hawlader., S.K. Chou, M.Z. Ullah, App. Therm. Eng. 21, pp. 1049-1065, (2001)

11. R .J. Fuller, Aquac. Eng. 36, pp. 250-260, (2007)

12. S. Kurpaska, Inż. Rol. 3, pp. 189-197, (2013) 